\section{Effect of Tubing Flush or Preconditioning on Available Insulin Concentration for IV Infusion: A Pilot Project}

\section{INTRODUCTION}

Insulin is commonly administered by continuous infusion for the management of hyperglycemia. Concerns exist about consistent delivery of insulin because there is adsorption of insulin to the infusion bag and tubing. ${ }^{1}$ Once equilibrium between the insulin binding sites and solution is attained, insulin delivery becomes consistent. Several factors influence the rate of equilibration, including flow rate, concentration of the insulin solution, and components of the delivery system. ${ }^{1}$ Tubing composition has a significant impact on insulin adsorption rates, and a range of $20 \%$ to $80 \%$ has been reported. ${ }^{2}$ With each solution change, the process of adsorption leads to inconsistency in insulin concentrations for many hours, putting patients at risk of morbidity and mortality associated with unanticipated hyperglycemia or hypoglycemia. ${ }^{3,4}$

Acceptable strategies to minimize the impact of insulin adsorption include flushing or preconditioning of the tubing. Flushing involves priming the tubing with a specified volume of insulin solution. Preconditioning involves priming the tubing with insulin solution, allowing the solution to dwell, and then flushing the tubing. Hewson and others ${ }^{1}$ found higher total insulin delivery and less variability in insulin concentration with preconditioned tubing. ${ }^{1}$ Thompson and others ${ }^{3}$ showed that dwell time did not affect the initial insulin concentration with polypropylene sets, but they did not determine whether there was an effect on insulin concentration during the infusion.

The objective of this study was to determine whether available insulin concentration differed between flushing and preconditioning of polyethylene-lined tubing.

\section{METHODS}

Two bags of insulin solution (0.1 units $/ \mathrm{mL}$, designated bag 1 and bag 2) were prepared by adding 50 units of regular human insulin (Humulin R, 100 units/mL, Lilly, Toronto, Ontario) to $500-\mathrm{mL}$ bags of $0.9 \%$ sodium chloride (Baxter, Mississauga, Ontario). The bags of insulin solution were then inverted several times and allowed to sit for $60 \mathrm{~s}$. A syringe was used to collect a sample from each bag (denoted as samples A and D, respectively) for determination of initial insulin concentration. A primary IV low-sorbing, polyethylene-lined tubing set (reference 2260-0500, Carefusion, Mississauga, Ontario [tubing set manufactured in Mexico]) was then connected to each bag. The tubing was $286 \mathrm{~cm}$ long, with a priming volume of $23 \mathrm{~mL}$. The infusion sets were primed with insulin solution, so that all air bubbles were eliminated.

For bag 1, the tubing was flushed with an additional $25 \mathrm{~mL}$ of the insulin solution. After completion of the flush (time 0 ), a sample of the effluent (designated sample B) was collected from the tubing. The insulin infusion was then initiated at $5 \mathrm{~mL} / \mathrm{h}$ using an Alaris PC pump (Carefusion). One hour later, another sample of the effluent (designated sample C) was collected from the tubing.

For bag 2, the tubing was preconditioned, as follows: the insulin solution in the primed tubing was allowed to dwell for $30 \mathrm{~min}$, and the tubing was then flushed with an additional $25 \mathrm{~mL}$ of insulin solution. After completion of the flush (time 0), a sample of the effluent (designated sample E) was collected from the tubing. The insulin infusion was then initiated at $5 \mathrm{~mL} / \mathrm{h}$ using the Alaris PC pump. One hour later, another sample of the effluent (designated sample F) was collected from the tubing.

For each sample, $0.04 \mathrm{~mL}$ of insulin solution was collected in a 1-mL syringe. The insulin solution was then immediately added to $30 \mathrm{~mL}$ of $5 \%$ human albumin (Grifols, Mississauga, Ontario), which is well known to prevent insulin adsorption to glass and plastic surfaces. The syringe containing insulin and albumin was then inverted 10 times. A portion of the solution was transferred into a red-top collection tube and frozen at $-20^{\circ} \mathrm{C}$ until analysis, about $28 \mathrm{~h}$. All of the samples were analyzed in a single day using the Roche electrochemiluminometric assay for human insulin on a Roche Cobas e601 analyzer, according to the manufacturer's instructions. This assay has an analytical measuring range of 15 to $6945 \mathrm{pmoL} / \mathrm{L}$ and observed coefficients of variation of $7 \%$ at $19.9 \mathrm{pmoL} / \mathrm{L}, 2 \%$ at $174 \mathrm{pmol} / \mathrm{L}$, and $2.3 \%$ at $494 \mathrm{pmol} / \mathrm{L}$.

\section{RESULTS}

The solution in the preconditioned tubing had higher concentrations of available insulin at time 0 and $1 \mathrm{~h}$ after infusion than did the solution in the flushed tubing (Table 1).

\section{DISCUSSION}

In this study, there was a difference in the available insulin concentration depending on whether the polyethylene-lined tubing was flushed or preconditioned. Both tubing-preparation methods 
Table 1. Available Insulin Concentration

\begin{tabular}{lcc} 
Bag and Sample* & $\begin{array}{c}\text { Insulin Concentration } \\
\text { (pmoL/L) }\end{array}$ & $\begin{array}{c}\text { \% Insulin } \\
\text { Relative to Bag }\end{array}$ \\
\hline Bag 1 (flushed tubing) & 1075.0 & - \\
A (bag) & 573.7 & 53.4 \\
B (at time 0) & 227.3 & 21.1 \\
C (at 1 h) & 1174.0 & - \\
\hline Bag 2 (preconditioned tubing) & 866.8 & 73.8 \\
D (bag) & 804.6 & 68.5 \\
E (at time 0) & & \\
F (at 1 h) & *Samples B, C, E, and F consisted of effluent from the polyethylene-lined tubing.
\end{tabular}

led to an available insulin concentration that was substantially lower than the initial insulin concentration. Preconditioning led to higher insulin concentrations that were more consistent over time $(73.8 \%$ at start of infusion and $68.5 \%$ after $1 \mathrm{~h}$ ). In contrast, flushing resulted in only $21 \%$ of the initial concentration being available after $1 \mathrm{~h}$. Similarly, Ley and others ${ }^{5}$ found that $34 \%$ of the anticipated insulin concentration was available at $1 \mathrm{~h}$.

Many strategies for tubing preparation have been reported to minimize variability in insulin delivery. ${ }^{1,-3-8}$ However, these studies had different variables, including tubing composition, insulin concentration, flow rates, and times of analysis. ${ }^{1,3,-8}$ Other factors influencing recommendations for insulin preparation include the amount of insulin solution that is wasted during insulin preparation and preparation time. ${ }^{3,6}$

With so many variables at play, a single strategy for administration of insulin may not ensure safe and effective concentrations of the drug for all scenarios. If polyethylene-lined tubing is used for insulin infusions, preconditioning of the tubing should be considered as a strategy for more consistent insulin delivery. A larger study is needed to determine the optimal preconditioning time for this tubing, as well as to assess the insulin concentration over $24 \mathrm{~h}$.

\section{References}

1. Hewson MP, Nawadra V, Oliver JR, Odgers C, Plummer JL, Simmer K. Insulin infusions in the neonatal unit: delivery variation due to adsorption. J Paediatr Child Health. 2000;36(3):216-20.

2. Greenwood BC, Chesnick MA, Szumita PM, Belisle C, Cotugno M. Stability of regular human insulin extemporaneously prepared in $0.9 \%$ sodium chloride in a polyvinyl chloride bag. Hosp Pharm. 2012;47(5):367-70.
3. Thompson CD, Vital-Carona J, Faustino EVS. The effect of tubing dwell time on insulin adsorption during intravenous insulin infusions. Diabetes Technol Ther. 2012;14(10):912-6.

4. Jacobi J, Bircher N, Krinsley J, Agus M, Braithwaite SS, Deutschman C, et al. Guidelines for the use of an insulin infusion for the management of hyperglycemia in critically ill patients. Crit Care Med. 2012;40(12):3251-76.

5. Ley SC, Ammann J, Herder C, Dickhaus T, Hartmann M, Kingden-Milles D. Insulin adsorption to catheter materials used for intensive insulin therapy in critically ill patients: polyethylene versus polyurethane-possible cause of variation in glucose control? Open Crit Care Med J. 2014;7:1-6.

6. Goldberg PA, Kedves A, Walter K, Groszmann A, Belous A, Inzucchi SE. "Waste not, want not": determining the optimal priming volume for intravenous insulin infusions. Diabetes Technol Ther. 2006;8(5):598-601.

7. Fuloria M, Friedberg MA, DuRant RH, Aschner JL. Effect of flow rate and insulin priming on the recovery of insulin from microbore infusion tubing. Pediatrics. 1998;102(6):1401-6.

8. Simeon PS, Geffner ME, Levin SR, Lindsey AM. Continuous insulin infusions in neonates: pharmacologic availability of insulin in intravenous solutions. J Pediatr. 1994;124(5 Pt 1):818-20.

Brandi Newby, BScPharm, ACPR

Coordinator, Neonatal and Pediatric Pharmacy

Surrey Memorial Hospital

Surrey, British Columbia

Daniel T Holmes, MD, FRCPC

Department of Pathology and Laboratory Medicine,

University of British Columbia

Department of Pathology and Laboratory Medicine,

St Paul's Hospital

Vancouver, British Columbia

Competing interests: None declared. 